Arts \& Humanities | James Jones

\section{The Neuropsychology of How Ritual Creates Religion}

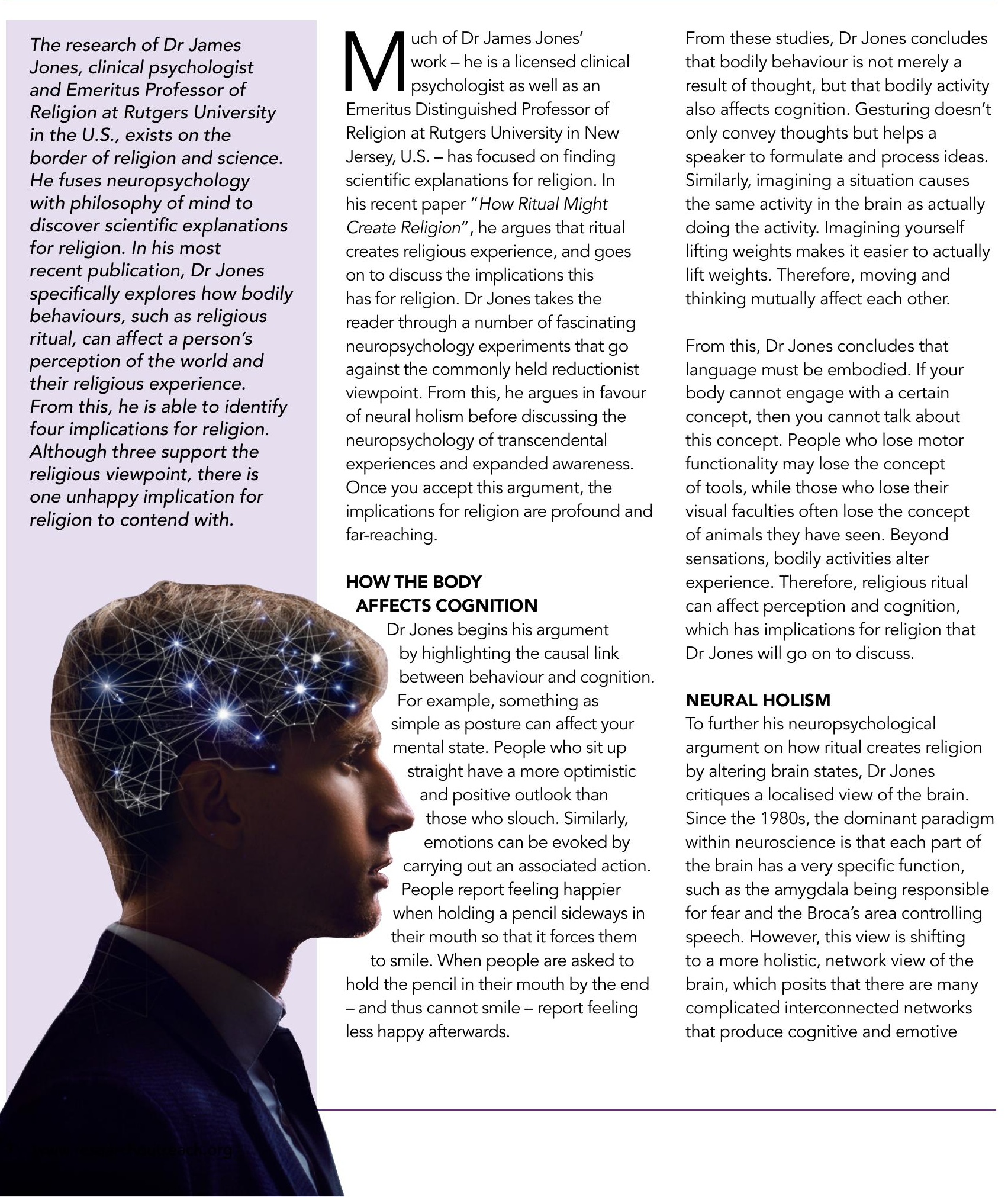

states. Brain imaging confirms that the concept of localisation is too simplistic. The amygdala is undoubtedly involved in fear, but it is also involved in sensory perception among other tasks. It
that no part of the brain is simply specialised. Furthermore, any act of cognition relies on several networks. Dr Jones highlights that reflecting on one's own mental state requires the 'mentalisation network' (which represents reality), the 'salience network' (which integrates external with intern stimuli) and the 'executive control network' (which is action-oriented). Cognition cannot be reduced to either a single region of the brain nor a single network. This means that cognition and emotion are not
completely distinct.

The attempt to fully map the brain and its networks carried out by the Huma holistic view of the brain. This project revealed a more complex and nuanced nature to cognition. This also further supports the claim that bodily activity including religious ritual, can affect cognition, emotion, and perception.

\section{NEUROPSYCHOLOGY OF}

EXPANDED AWARENES

Dr Jones has now shown that the body affects cognition and that the brain should be viewed from the perspective of neural holism. Next, he delves into the idea of expanded awareness, which is a common effect of religious ritual. state, which involves experience which goes beyond the ordinary everyday experience received through the five senses, Religious rituals contribute to a person experiencing transcendence. Dr Jones attempts to explain the neuropsychology behind these higherlevel experiences.

Abstract rationality is embedded in complex and dense networks. The Human Connectome Project finds tha reason, emotion, and sensation all work together using the same neura networks. Working together, they generate a more transcendental way of knowing. This suggests that huma understanding is never purely reason
driven. The mind is also made up of

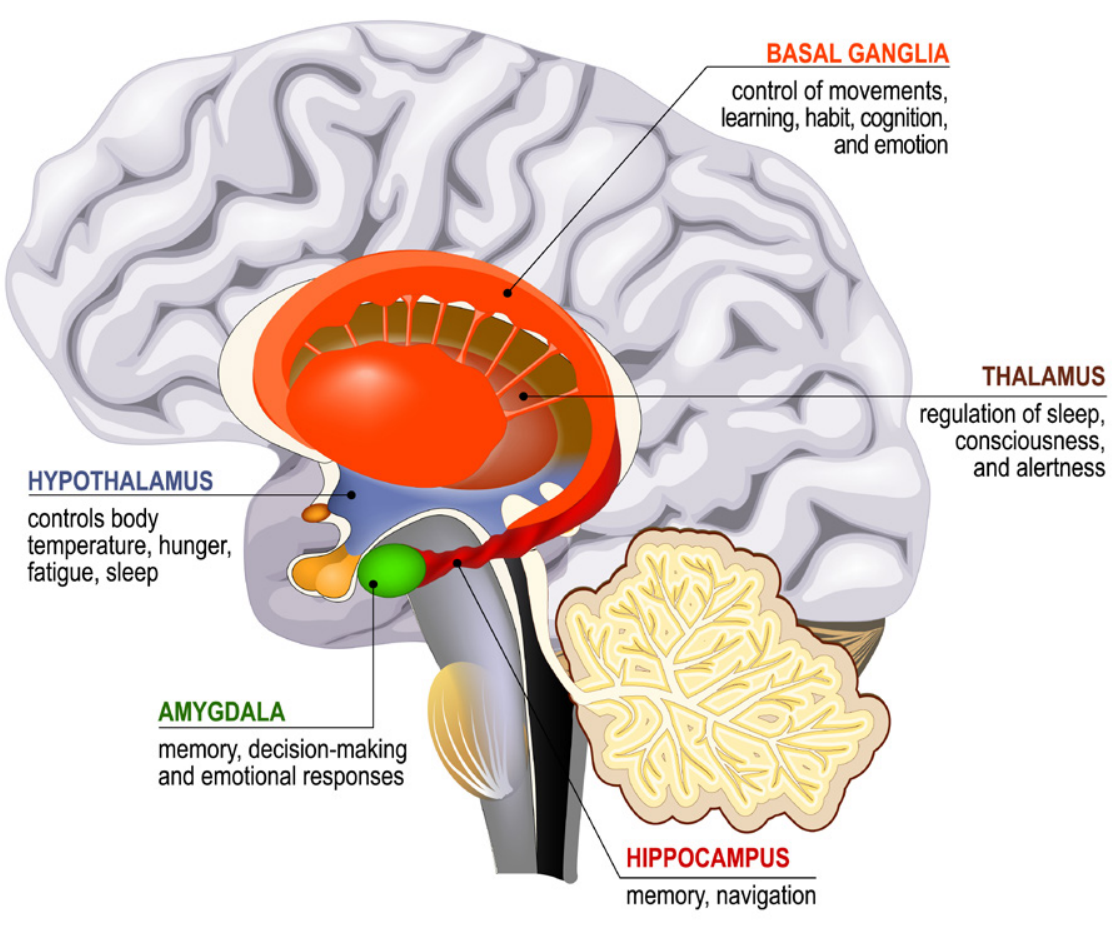

While each part of the brain has a certain function, the hol
of cognition relies on several interconnected networks

Reason, emotion, and sensation all work together using the same neural networks. two subsystems: unconscious cognition, conscious cognition, which is slower and
which intive and fastreacting and

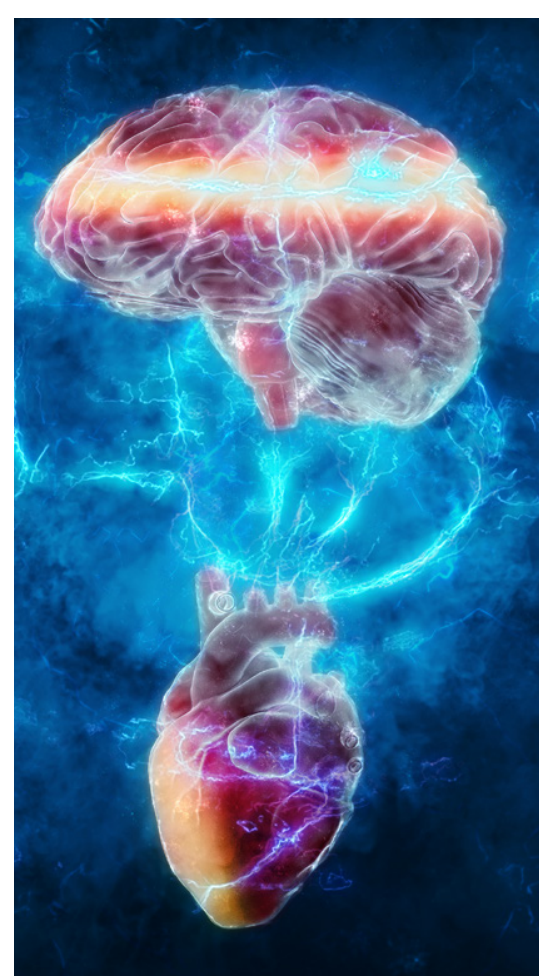

more deliberate. These two sub-systems one another.

While the brain has two hemispheres, the claim that the right hemisphere is artistic and intuitive while the left 政 involved in nearly all cognitive processes and interact with each other in different ways. Dr Jones' neuropsychology posits that is, transcendental result in a larger, world by joining bodily activity, intuition, cognition, and emotion.

IMPLICATIONS FOR RELIGION After explaining how the body affects cognition, why neural holism should be the dominant paradigm, and the neuropsychology of expanded avareness, Dr Jones is ready to set out the implications this has for religion. He of which are four implications, three viewpoint and one which he describes viewpoint, and one which he describes
as the "final, unhappy implication". 


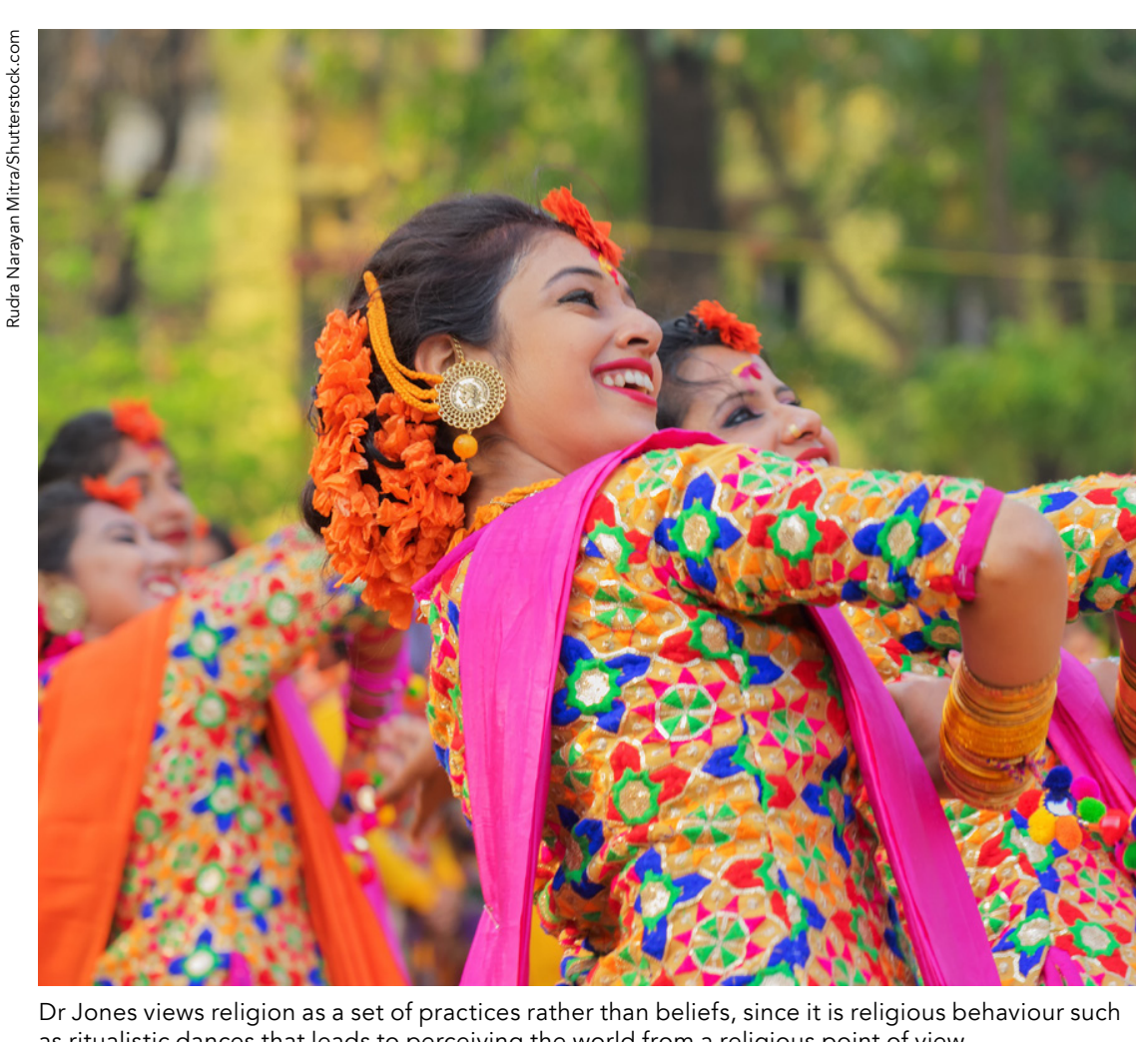

Religious knowledge is only available to those who engage in religious practices and becomes more accessible the more they do so.

Firstly, Dr Jones discusses the brain as an open system. This refers to the aforementioned deep and complex networks contained within the brain. Even the most reductionist philosopher, breaking down the brain to its constituent parts, cannot view the brain as anything neurophysiogy that Dr Jones sets out paints the brain as a more open system, in which connections are non-linear. Neuroplasticity means that each brain is unique and constantly changing, and it is difficult to reduce cognition to purely Newtonian physicalism. This fits the nondeterminist view that religious believers tend to hold.

Secondly, Dr Jones explores the implications for religion of an increasingly complex epistemology. In other words, knowledge cannot be gained from simple sensations alone. The argument Dr Jones sets out above suggests that our perception of the world goes beyon merely forming a mental representa
of reality. Epistemology is far more widely held ing but it has ber a importance that religion has placed on ritual in generating transcendental mental states. The implication for
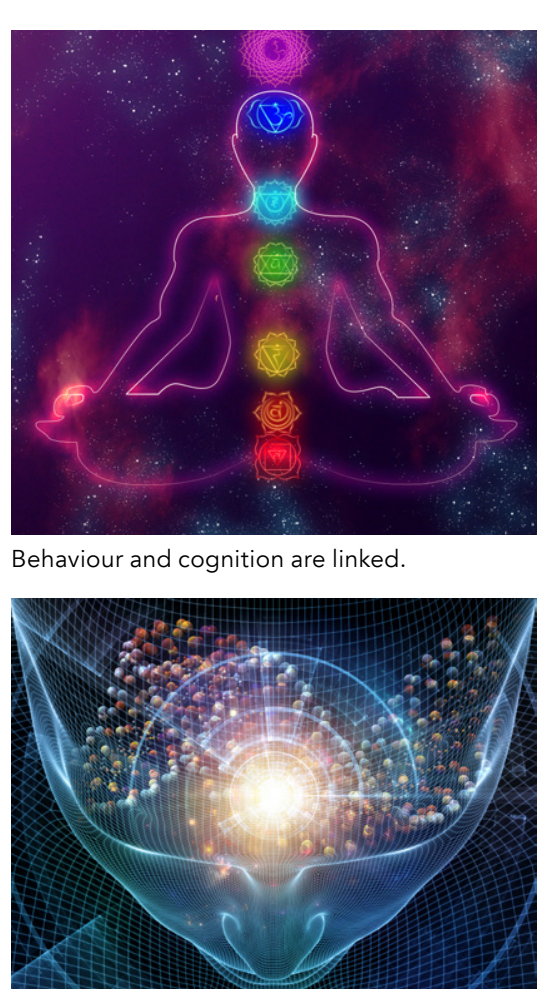

A person might experiense
through religious rituals.

religion is that religion is not, and cannot simply be explained by a set of beliefs. Instead, Dr Jones views religion as a se of practices, since it is these religious behaviours that lead to perceiving the

Finally, Dr Jones reveals an "unhappy implication". As a result of the first three implications, religious knowledge is only available to those who engage in religious practices and becomes more accessible the more they do so. This is pecause religious rituals transform the of the world Dr Jones likens this to being able to identify a fine wine from problem from a brain scan. In this sense, religion must be learned through ritual and is not available to those who do no engage in these rituals.

If Dr Jones is correct, then the Though the religious viewpoint benefits from being understood as embodied activity, as well as the complex, holistic nature of the brain, there is still an unhappy truth to face. If religion is true, then this truth can only be known by be be accessed by people who do not implications for religion are significant.

\section{Behind the Research}

\section{Dr James Jones}

A A: J: jamwjones3@cs.com T: +17327280969 Mobile: +19084894920 world from a religious point of view. taste alone or spotting a neurological

Research Objectives

Dr James Jones, clinical psychologist and Emeritus Professor of Religion, takes a neuropsychological view on religious experiences.

\section{Detail}

Dr James W. Jones

510 Ocean Ave, Apt 30

USA

\section{Bio}

James W. Jones earned two doctorates and an Honorary Doctorate, is Emeritus Distinguished Professor of Religion at Rutgers University in the United States, the author of fifteen books and numerous papers, fellow of the American Psychological Association, former Vice President of the International Association for the Psychology of Religion, a fellow of the International Society for Science and Religion, and a licensed clinical psychologist.

Funding

John Templeton Foundation, Rutgers Universit

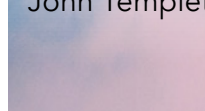
The use of yogious belief for centuries. breathing yoga, meditation, and to be true by neurophysiological

\section{References}

Jones, J. (2020). How Ritual Might Create Religion. Archive for the Psychology of Religion, 42(1), 29-45. Available at: https://doi.org/10.1177/0084672420903112

Jones, J. (2019). Living Religion: Embodiment, Theology, and the Possibility of a Spiritual Sense. Oxford University
Press, 94-149.

Jones, J. (2016). Can Science Explain Religion? The Cognitive Science Debate. Oxford University Press, 176-191.

\section{Personal Response}

How significant are the implications of the finding Human Connectome Project for religion?

II The cognitive science of religion (CSR), like all evolutionary psychology, has traditionally relied on
a massively modular view of cognitive processing supported by a modular view of the brain. This modularity assumption underlies CSR theorising about Human Connectome Project and the shift to network models undercuts this modular view and much of the theorising about religion based on it. In addition, much psychological and philosophical discussion of religion has been carried out in terms of a series of categorical dichotomies or separations, such as reason is some heuristic value in seeing these categories as referring to separate domains, this dichotomisation is too drastic and over-simplifies our understanding of religion (e.g. "it's all just emotion"). The Human level such dichotomising is not well-founded and that in the process of human understanding reaso emotion and intuition (however one understands it) as often mutually influence each other. This is what I mean
by a more complex epistemology. well as sensation and perception are all involved and 